\title{
Method of controlling innovative articulation for articulated vehicle
}

\author{
Mateusz Szumilas ${ }^{1,}$, Sergiusz Łuczak ${ }^{1}$, Maciej Bodnicki ${ }^{1}$, Marcin Stożek ${ }^{2}$, \\ Tomasz Załuski ${ }^{2}$ \\ ${ }^{1}$ Warsaw University of Technology, Faculty of Mechatronics, ul. Boboli 8, 02-525 Warszawa, Poland \\ ${ }^{2}$ EC Engineering Sp. z o.o., ul. Jasnogórska 9, 31-358 Kraków, Poland
}

\begin{abstract}
Operation of an articulated vehicle is dependent on an appropriate damping action taking place in its rotary articulation. In order to analyse an impact of the control of the articulation on the motion of the vehicle a model of the vehicle with a controllable hydraulic damping system has been developed. A 90 degree turn and lane change manoeuvres were simulated using LabVIEW software. Modification of the damping parameters of the articulation, according to the velocity and articulation angle of the vehicle, proved to have a significant impact on the vehicle motion stability. Moreover, the sensor layer necessary for the control algorithm as well as the diagnostic system is described.
\end{abstract}

Keywords: articulated vehicle, simulation, hydraulic damping, LabVIEW, MEMS

\section{Introduction}

Articulated urban buses play an important role in the organisation of public transport. They provide high passenger capacity needed in big and constantly growing cities. Such buses operate in a high traffic and on routes comprising narrow roads and sharp turns. In addition, these vehicles have to develop high speeds when they enter the arterial roads or expressways. The use of a rotary articulation allows articulated buses to take sharper turns than conventional buses having equal overall length. At the same time, articulated vehicles are under risk of developing uncontrolled pivoting movements of rear and front sections with respect to one another, especially when the rear axle is driven, which is a popular arrangement for low floor vehicles. Under such conditions of operation the articulation has to provide low damping when driving at low speed and, on the contrary, increase the damping when the bus is heading straight or is changing lane at a high speed. Stiffness of the articulation can be controlled with a proper setup of hydraulic dampers combined with electro-hydraulic valves.

The paper presents an implementation and verification of a control algorithm proposed for the articulation with hydraulic damping. The verification is based on the analysis of the results of simulation of the articulated vehicle performing a 90 degree turn and lane change

\footnotetext{
* Corresponding author: m.szumilas@mchtr.pw.edu.pl

Reviewers: Bogdan Posiadala, Krzysztof Talaśka
} 
manoeuvres. Moreover, a sensor layer employed by the control algorithm is described. The proposed sensor layer has been enhanced so that it can be also used for diagnostic purposes.

\section{Method}

In order to analyse impact of the articulation control algorithm on the motion of the articulated vehicle a planar model has been developed. The model includes a hydraulic damping system used in the articulation. Similar planar models developed for articulated vehicles, especially for tractor and trailer configurations, can be found in [1-3].

The following assumptions were made for the model:

- the vehicle is reconstructed by its single track model;

- there are no roll and pitch motions of the vehicle, only rotation around the yaw axis;

- normal forces acting on the tyres are computed under the static load conditions;

- aerodynamics of the vehicle is not considered.

\subsection{The vehicle model}

The articulated bus is modelled as two rigid bodies including front and rear unit. The front unit has a steerable axle and an unpowered middle axle. The rear unit has one powered axle. These two units are connected by a rotational joint. The model is described in the three coordinate systems:

- the inertial coordinate system fixed to the ground $\left(\mathrm{X}_{\mathrm{z}} \mathrm{Y}_{\mathrm{z}}\right)$;

- the front unit coordinate system $\left(\mathrm{X}_{1} \mathrm{C}_{1} \mathrm{Y}_{1}\right)$, with its origin at the centre of gravity of this unit $\left(\mathrm{C}_{1}\right)$ and a yaw velocity $\omega_{l}$;

- the rear unit coordinate system $\left(\mathrm{X}_{2} \mathrm{C}_{2} \mathrm{Y}_{2}\right)$, with its origin at the centre of gravity of this unit $\left(\mathrm{C}_{2}\right)$ and a yaw velocity $\omega_{2}$.

The geometrical and inertial parameters of the single track model of the vehicle are presented in Fig. 1. The $m_{1}, m_{2}$ are masses and the $J_{1}, J_{2}$ are mass moments of inertia about the vertical central axes of the front and rear units respectively.

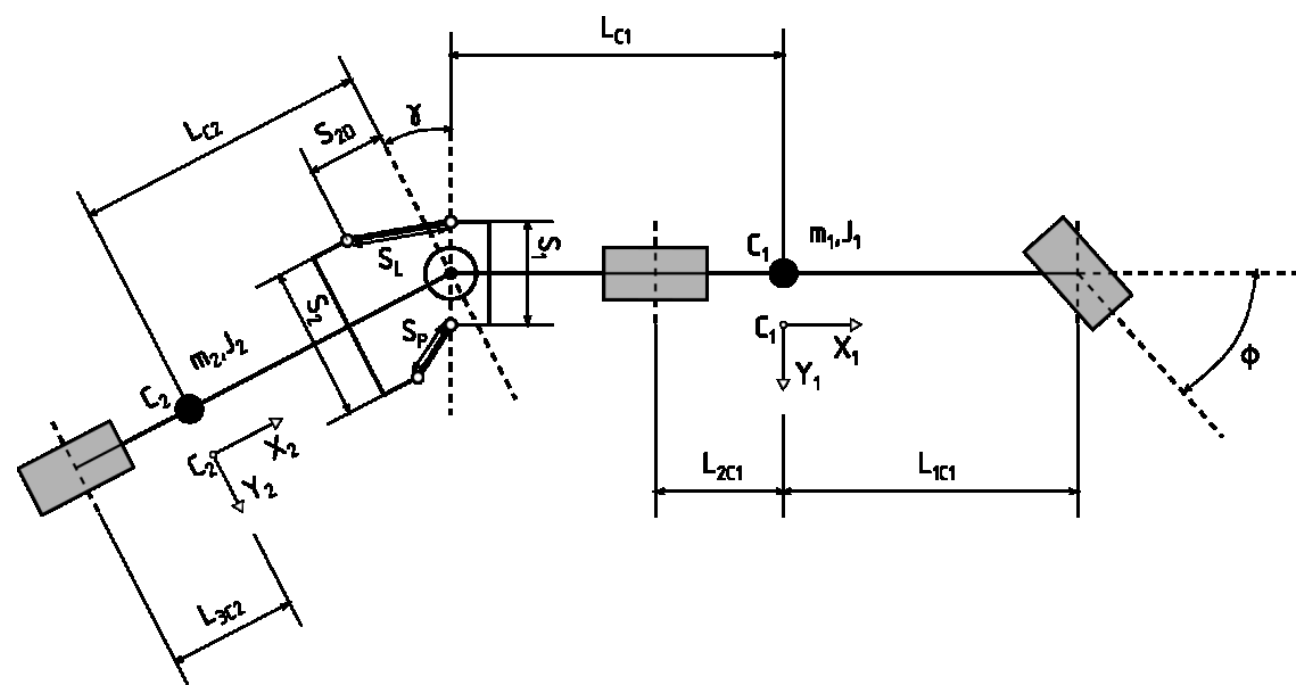

Fig. 1. The geometrical and inertial parameters of the single track model of the articulated bus 
The dimensions and forces acting in the articulation are presented in Fig. 2. The relationship between angle $\beta$ and articulation angle $\gamma$ is:

$$
\beta_{\mathrm{L}}=\beta_{0}+\gamma, \beta_{\mathrm{P}}=\beta_{0}-\gamma
$$

where:

$$
\beta_{0}=90^{\circ}-\arctan \left(\frac{\left(\frac{\mathrm{s}_{2}}{2}\right)}{\mathrm{S}_{2 \mathrm{D}}}\right)
$$

The lengths of the hydraulic dampers are:

$$
\mathrm{S}_{\mathrm{L} / \mathrm{P}}=\sqrt{\left(\frac{\mathrm{S}_{1}}{2}\right)^{2}+\left(\frac{\mathrm{S}_{2}}{2}\right)^{2}+\mathrm{S}_{2 \mathrm{D}}{ }^{2}-2\left(\frac{\mathrm{S}_{1}}{2}\right)\left(\sqrt{\left(\frac{\mathrm{S}_{2}}{2}\right)^{2}+\mathrm{S}_{2 \mathrm{D}}{ }^{2}}\right) \cos \left(\beta_{\mathrm{L} / \mathrm{P}}\right)}
$$

The individual angles in the articulated joint can be expressed as:

$$
\begin{gathered}
\alpha_{2 \mathrm{~L} / \mathrm{P}}=\arcsin \left(\frac{\frac{\mathrm{S}_{1}}{2} \sin \beta_{\mathrm{L} / \mathrm{P}}}{\mathrm{S}_{\mathrm{L} / \mathrm{P}}}\right)+\arctan \frac{\mathrm{S}_{2 \mathrm{D}}}{\left(\frac{\mathrm{S}_{2}}{2}\right)} \\
\alpha_{1 \mathrm{~L}}=180^{\circ}-\gamma-\alpha_{2 \mathrm{~L}}, \alpha_{1 \mathrm{P}}=180^{\circ}+\gamma-\alpha_{2 \mathrm{P}}
\end{gathered}
$$
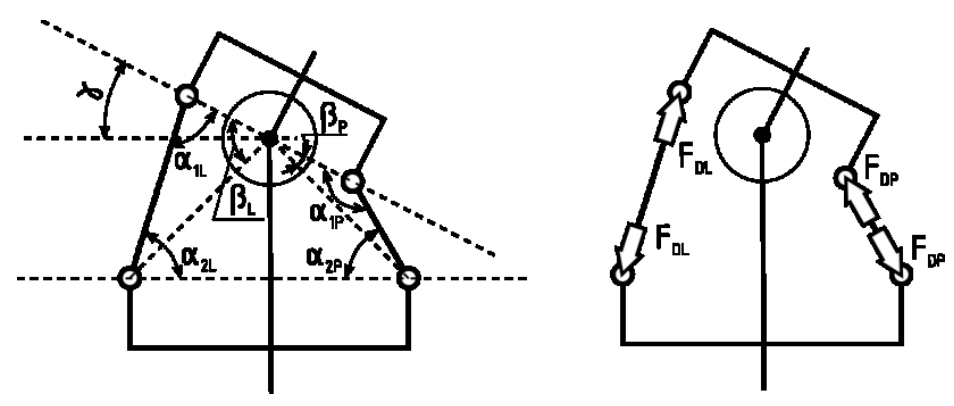

Fig. 2. The dimensions and forces acting in the articulated joint

The speed of articulation is given by equation:

$$
\dot{\gamma}=\omega_{1}-\omega_{2}
$$

The accelerations of the centres of gravity of the vehicle's front and rear units in their respective coordinate systems (Fig. 3) are as follows:

$$
\begin{array}{ll}
a_{1 X}=\dot{V}_{1 X}-\omega_{1} V_{C 1 Y} & a_{1 Y}=\dot{V}_{C 1 Y}+\omega_{1} V_{1 X} \\
a_{2 X}=\dot{V}_{2 X}-\omega_{2} V_{C 2 Y} & a_{2 Y}=\dot{V}_{C 2 Y}+\omega_{2} V_{2 X}
\end{array}
$$

The slip angles of the tyres are:

$$
\begin{gathered}
\delta_{\mathrm{k} 1}=\arctan \frac{\mathrm{V}_{\mathrm{k} 1 \mathrm{Y}}}{\mathrm{V}_{1 \mathrm{X}}}-\phi \wedge \mathrm{V}_{\mathrm{k} 1 \mathrm{Y}}=\mathrm{V}_{\mathrm{C} 1 \mathrm{Y}}+\omega_{1} \mathrm{~L}_{1 \mathrm{C} 1} \\
\delta_{\mathrm{k} 2}=\arctan \frac{\mathrm{V}_{\mathrm{k} 2 \mathrm{Y}}}{\mathrm{V}_{1 \mathrm{X}}} \wedge \mathrm{V}_{\mathrm{k} 2 \mathrm{Y}}=\mathrm{V}_{\mathrm{C} 1 \mathrm{Y}}-\omega_{1} \mathrm{~L}_{2 \mathrm{C} 1} \\
\delta_{\mathrm{k} 3}=\arctan \frac{\mathrm{V}_{\mathrm{k} 3 \mathrm{Y}}}{\mathrm{V}_{2 \mathrm{X}}} \wedge \mathrm{V}_{\mathrm{k} 3 \mathrm{Y}}=\mathrm{V}_{\mathrm{C} 2 \mathrm{Y}}-\omega_{2} \mathrm{~L}_{3 \mathrm{C} 2}
\end{gathered}
$$


The forces acting in the articulated joint (Fig. 2, Fig. 4) are as follows:

$$
\begin{array}{ll}
\mathrm{a}_{1 \mathrm{X}}=\dot{\mathrm{V}}_{1 \mathrm{X}}-\omega_{1} \mathrm{~V}_{\mathrm{C} 1 \mathrm{Y}} & \mathrm{a}_{1 \mathrm{Y}}=\dot{\mathrm{V}}_{\mathrm{C} 1 \mathrm{Y}}+\omega_{1} \mathrm{~V}_{1 \mathrm{X}} \\
\mathrm{a}_{2 \mathrm{X}}=\dot{\mathrm{V}}_{2 \mathrm{X}}-\omega_{2} \mathrm{~V}_{\mathrm{C} 2 \mathrm{Y}} & \mathrm{a}_{2 \mathrm{Y}}=\dot{\mathrm{V}}_{\mathrm{C} 2 \mathrm{Y}}+\omega_{2} \mathrm{~V}_{2 \mathrm{X}}
\end{array}
$$
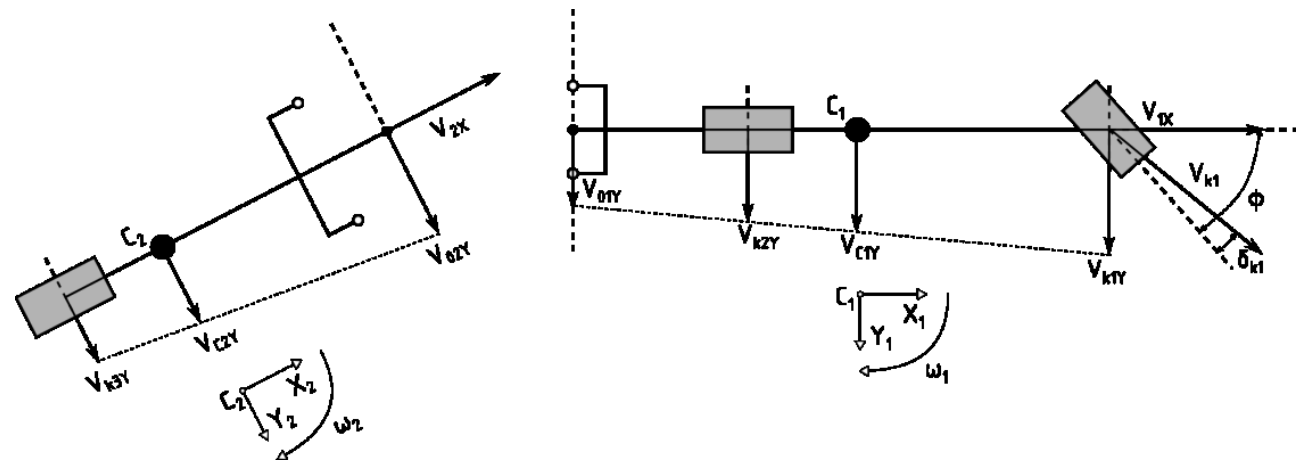

Fig. 3. The kinematics of the articulated vehicle
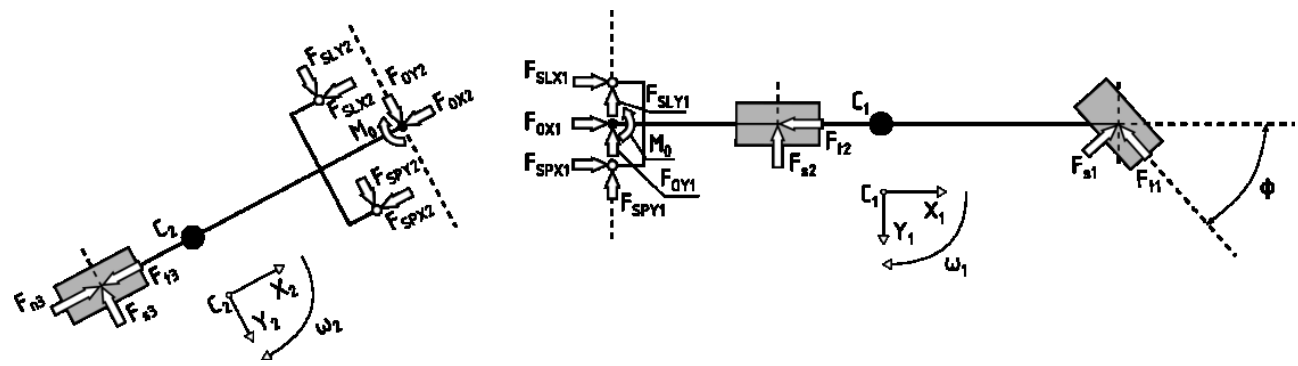

Fig. 4. The dynamics of the articulated vehicle

The forces acting in the articulated joint (Fig. 2, Fig. 4) are as follows:

$$
\begin{array}{ll}
\mathrm{F}_{\mathrm{SLX} 1}=\mathrm{F}_{\mathrm{DL}} \sin \alpha_{1 \mathrm{~L}} & \mathrm{~F}_{\mathrm{SLY} 1}=\mathrm{F}_{\mathrm{DL}} \cos \alpha_{1 \mathrm{~L}} \\
\mathrm{~F}_{\mathrm{SPX} 1}=\mathrm{F}_{\mathrm{DP}} \sin \alpha_{1 \mathrm{P}} & \mathrm{F}_{\mathrm{SPY} 1}=-\mathrm{F}_{\mathrm{DP}} \cos \alpha_{1 \mathrm{P}} \\
\mathrm{F}_{\mathrm{SLX} 2}=\mathrm{F}_{\mathrm{DL}} \sin \alpha_{2 \mathrm{~L}} & \mathrm{~F}_{\mathrm{SLY} 2}=-\mathrm{F}_{\mathrm{DL}} \cos \alpha_{2 \mathrm{~L}} \\
\mathrm{~F}_{\mathrm{SPX} 2}=\mathrm{F}_{\mathrm{DP}} \sin \alpha_{2 \mathrm{P}} & \mathrm{F}_{\mathrm{SPY} 2}=\mathrm{F}_{\mathrm{DP}} \cos \alpha_{2 \mathrm{P}}
\end{array}
$$

The forces acting on the steerable axle in the front unit coordinate system:

$$
\mathrm{F}_{1 \mathrm{X} 1}=-\mathrm{F}_{\mathrm{t} 1} \cos \phi+\mathrm{F}_{\mathrm{s} 1} \sin \phi \quad \mathrm{F}_{1 \mathrm{Y} 1}=-\mathrm{F}_{\mathrm{t} 1} \sin \phi-\mathrm{F}_{\mathrm{s} 1} \cos \phi
$$

The final equations representing the planar motion of the articulated vehicle:

$$
\begin{gathered}
\left(\mathrm{m}_{1}+\mathrm{m}_{2}\right)\left(\dot{\mathrm{V}}_{1 \mathrm{X}}-\omega_{1} \mathrm{~V}_{\mathrm{C} 1 \mathrm{Y}}\right)+\mathrm{m}_{2}\left(\omega_{1}^{2} \mathrm{~L}_{\mathrm{C} 1}+\omega_{2}^{2} \mathrm{~L}_{\mathrm{C} 2} \cos \gamma-\dot{\omega}_{2} \mathrm{~L}_{\mathrm{C} 2} \sin \gamma\right)= \\
=\cos \gamma\left(\mathrm{F}_{\mathrm{n} 3}-\mathrm{F}_{\mathrm{t} 3}-\mathrm{F}_{\mathrm{SLX} 2}-\mathrm{F}_{\mathrm{SPX} 2}\right)-\sin \gamma\left(\mathrm{F}_{\mathrm{s} 3}-\mathrm{F}_{\mathrm{SPY} 2}-\mathrm{F}_{\mathrm{SLY} 2}\right)+ \\
+\mathrm{F}_{\mathrm{SLX} 1}+\mathrm{F}_{\mathrm{SPX} 1}-\mathrm{F}_{\mathrm{t} 2}+\mathrm{F}_{1 \mathrm{X} 1} \\
\left(\mathrm{~m}_{1}+\mathrm{m}_{2}\right)\left(\dot{\mathrm{V}}_{\mathrm{C} 1 \mathrm{Y}}+\omega_{1} \mathrm{~V}_{1 \mathrm{X}}\right)-\mathrm{m}_{2}\left(\dot{\omega}_{1} \mathrm{~L}_{\mathrm{C} 1}+\omega_{2}^{2} \mathrm{~L}_{\mathrm{C} 2} \sin \gamma+\dot{\omega}_{2} \mathrm{~L}_{\mathrm{C} 2} \cos \gamma\right)= \\
=-\sin \gamma\left(\mathrm{F}_{\mathrm{n} 3}-\mathrm{F}_{\mathrm{t} 3}-\mathrm{F}_{\mathrm{SLX} 2}-\mathrm{F}_{\mathrm{SPX} 2}\right)-\cos \gamma\left(\mathrm{F}_{\mathrm{s} 3}-\mathrm{F}_{\mathrm{SPY} 2}-\mathrm{F}_{\mathrm{SLY} 2}\right)- \\
-\mathrm{F}_{\mathrm{SLY} 1}-\mathrm{F}_{\mathrm{SPY} 1}-\mathrm{F}_{\mathrm{s} 2}+\mathrm{F}_{1 \mathrm{Y} 1}
\end{gathered}
$$




$$
\begin{gathered}
\mathrm{J}_{1} \dot{\omega}_{1}=\mathrm{F}_{1 \mathrm{Y} 1} \mathrm{~L}_{1 \mathrm{C} 1}+\mathrm{F}_{\mathrm{s} 2} \mathrm{~L}_{2 \mathrm{C} 1}-\mathrm{M}_{\mathrm{O}}+\frac{\mathrm{s}_{1}}{2}\left(\mathrm{~F}_{\mathrm{SLX} 1}-\mathrm{F}_{\mathrm{SPX} 1}\right)+ \\
+\mathrm{L}_{\mathrm{C} 1}\left[\mathrm{~F}_{1 \mathrm{Y} 1}-\mathrm{F}_{\mathrm{S} 2}-\mathrm{m}_{1}\left(\dot{\mathrm{V}}_{\mathrm{C} 1 \mathrm{Y}}+\omega_{1} \mathrm{~V}_{1 \mathrm{X}}\right)\right] \\
\mathrm{J}_{2} \dot{\omega}_{2}=\mathrm{F}_{\mathrm{S} 3} \mathrm{~L}_{3 \mathrm{C} 2}+\mathrm{M}_{\mathrm{O}}+\frac{\mathrm{s}_{2}}{2}\left(\mathrm{~F}_{\mathrm{SPX} 2}-\mathrm{F}_{\mathrm{SLX} 2}\right)-\mathrm{S}_{2 \mathrm{D}}\left(\mathrm{F}_{\mathrm{SLY} 2}+\mathrm{F}_{\mathrm{SPY} 2}\right)+ \\
+\mathrm{L}_{\mathrm{C} 2}\left\{F_{s 3}+m_{2}\left[\sin \gamma\left(\dot{V}_{1 X}-\omega_{1} V_{C 1 Y}+\omega_{1}^{2} L_{C 1}\right)+\right.\right. \\
\left.\left.+\cos \gamma\left(\dot{V}_{C 1 Y}+\omega_{1} V_{1 X}-\dot{\omega}_{1} L_{C 1}\right)-\dot{\omega}_{2} L_{C 2}\right]\right\}
\end{gathered}
$$

\subsection{The tyre model}

The traction forces acting on each wheel of the vehicle are calculated assuming constant rolling resistance coefficient (19). The equation introduces nonlinearity for low longitudinal velocities of the wheel with accordance to:

$$
\mathrm{F}_{\mathrm{tn}}=\mathrm{F}_{\mathrm{kzn}} \mathrm{C}_{\mathrm{rr}} \tanh \left(\frac{\left|\mathrm{V}_{\mathrm{kXn}}\right|}{\mathrm{v}_{\mathrm{thr}}}\right)
$$

where: $F_{t n}$ and $F_{k z n}$ are the longitudinal (traction) and normal forces, respectively, acting on the wheel which belongs to the $n$-th axle, $C_{r r}$ is the rolling resistance coefficient, $V_{k X n}$ is the $\mathrm{X}$ component of the velocity of the wheel axle (i.e. in the rolling direction), $V_{t h r}$ is the threshold velocity.

The side forces acting on the tyres (these forces are responsible for adjusting the driving direction of the vehicle) are calculated according to the Dugoff model [4]. The longitudinal slip is omitted in this model. The side slip angle of the $n$-th axle is given with:

$$
\alpha_{\mathrm{n}}=\tan \frac{\mathrm{V}_{\mathrm{kYn}}}{\mathrm{V}_{\mathrm{kXn}}}
$$

The equations of the Dugoff model are as follows:

$$
\begin{gathered}
\lambda=\frac{\mu \mathrm{F}_{\mathrm{kzn}}\left(1-\epsilon \mathrm{V}_{\mathrm{kXn}} \sqrt{\mathrm{s}_{\mathrm{n}}^{2}+\tan ^{2} \alpha_{\mathrm{n}}}\right)\left(1-\mathrm{s}_{\mathrm{n}}\right)}{2 \sqrt{\left(\mathrm{K}_{\mathrm{sn}} s_{\mathrm{n}}\right)^{2}+\left(\mathrm{K}_{\mathrm{n}} \tan \alpha_{\mathrm{n}}\right)^{2}}} \\
F_{S n}=\frac{K_{n} \tan \alpha_{n}}{1-s_{n}} f(\lambda) \quad \wedge \mathrm{f}(\lambda)= \begin{cases}\lambda(2-\lambda) & \text { if } \lambda<1 \\
1 & \text { if } \lambda \geq 1\end{cases}
\end{gathered}
$$

where: $F_{s n}$ is the lateral force acting on the wheel which belongs to the $n$-th axle, $V_{k Y n}$ is the $\mathrm{Y}$ component of the velocity of the wheel axle (i.e. perpendicular to the rolling direction), $K_{n}$ is the cornering stiffness of the tyre, $K_{s n}$ is the longitudinal stiffness of the tyre, $\varepsilon$ is the friction reduction coefficient, $\mu$ is the nominal tyre-ground friction coefficient, $s_{n}$ is the longitudinal slip ratio.

\subsection{The damper model}

The hydraulic damper (Fig. 5) is an important part of the discussed articulation. The hydraulic setup of the articulation consists of two cylinders, each paired with an electrically-driven proportional valve. 


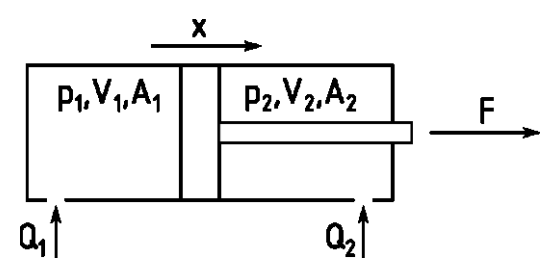

Fig. 5. The model of the hydraulic damper

The piston motion is modelled with the following equations [5-6]:

$$
\begin{aligned}
& \left\{\begin{array}{l}
\frac{\mathrm{dp}_{1}}{\mathrm{dt}}=\frac{\mathrm{K}_{\mathrm{bm}}}{\mathrm{V}_{1}}\left(\mathrm{Q}_{1}-\mathrm{A}_{1} \frac{\mathrm{dx}}{\mathrm{dt}}\right) \wedge \mathrm{V}_{1}=\mathrm{V}_{0 / 1}+\mathrm{A}_{1} \mathrm{x} \\
\frac{\mathrm{dp_{2 }}}{\mathrm{dt}}=\frac{\mathrm{K}_{\mathrm{bm}}}{\mathrm{V}_{2}}\left(\mathrm{Q}_{2}+\mathrm{A}_{2} \frac{\mathrm{dx}}{\mathrm{dt}}\right) \wedge \mathrm{V}_{2}=\mathrm{V}_{0 / 2}-\mathrm{A}_{2} \mathrm{x}
\end{array}\right. \\
& \mathrm{F}=\mathrm{p}_{2} \mathrm{~A}_{2}-\mathrm{p}_{1} \mathrm{~A}_{1}
\end{aligned}
$$

where: $x$ is the piston position, $F$ is the force acting on the piston, $K_{b m}$ is the bulk modulus of the hydraulic fluid, $p_{n}$ is the pressure in the $n$-th chamber, $Q_{n}$ is the volumetric flow to the $n$-th chamber, $V_{0 / n}$ is the initial volume of the $n$-th chamber, $V_{n}$ is the volume of the $n$-th chamber, $A_{n}$ is the cross-sectional area of the piston in the $n$-th chamber.

The fluid flow through the proportional valve is as follows:

$$
\begin{gathered}
\mathrm{Q}_{\mathrm{Z}}=\mathrm{A}_{\text {orif }} \mathrm{C}_{\mathrm{d}} \sqrt{\frac{2|\Delta \mathrm{p}|}{\rho}} \operatorname{sgn}(\Delta \mathrm{p}) \\
\mathrm{Q}_{1}=-\mathrm{Q}_{2}=\mathrm{Q}_{\mathrm{Z}} \wedge \Delta \mathrm{p}=\mathrm{p}_{2}-\mathrm{p}_{1}
\end{gathered}
$$

where: $\Delta p$ is the pressure drop across the valve, $\rho$ is the hydraulic fluid density, $A_{\text {orif }}$ is the valve opening area, $C_{d}$ is the discharge coefficient.

The opening area of the proportional valve is adjusted by the valve itself and it depends on the pressure drop across the valve and on the set point value. The opening area is modelled according to the equations:

$$
\begin{gathered}
\mathrm{A}_{\text {orif }}(\Delta \mathrm{p})=\left\{\begin{array}{cc}
\mathrm{A}_{\text {orif_min }} & \text { if } \Delta \mathrm{p} \leq \mathrm{p}_{\text {set }} \\
\mathrm{A}_{\text {orif_min }}+\mathrm{k}\left(\Delta \mathrm{p}-\mathrm{p}_{\text {set }}\right) & \text { if } \mathrm{p}_{\text {set }}<\Delta p \leq \mathrm{p}_{\text {set }}+\mathrm{p}_{\text {reg }} \\
\mathrm{A}_{\text {orif_max }} & \text { if } \mathrm{p}_{\text {set }}+\mathrm{p}_{\text {reg }}<\Delta p
\end{array}\right. \\
\mathrm{k}=\frac{\mathrm{A}_{\text {orif_max }}-\mathrm{A}_{\text {orif_min }}}{\mathrm{p}_{\text {reg }}}
\end{gathered}
$$

where: $A_{\text {orif_min }}$ is the smallest opening area, $A_{\text {orif_max }}$ is the largest opening area, $p_{\text {set }}$ is the valve set point, $p_{\text {reg }}$ is the pressure regulation range.

\subsection{The control algorithm}

The control algorithm of the articulation mechanism is presented in Fig. 6. Taking as inputs information about articulation angle, vehicle speed, angular position of the steering wheel and vehicle emergency state (i.e., occurrence of collision, slip, excessive articulation angle, rapid deceleration, joint malfunction), the algorithm outputs the required damping level. 
The damping level control is achieved by setting the pressure drop across the proportional valves of the dampers as follows:
- no damping:
$\Delta p=5 \cdot 10^{5} \mathrm{~Pa}$
- $1^{\text {st }}$ order damping:
- $2^{\text {nd }}$ order damping:
$\triangle p=60 \cdot 10^{5} \mathrm{~Pa}$
- dampers locked:
$\Delta p=120 \cdot 10^{5} \mathrm{~Pa}$
$\Delta p=220 \cdot 10^{5} \mathrm{~Pa}$

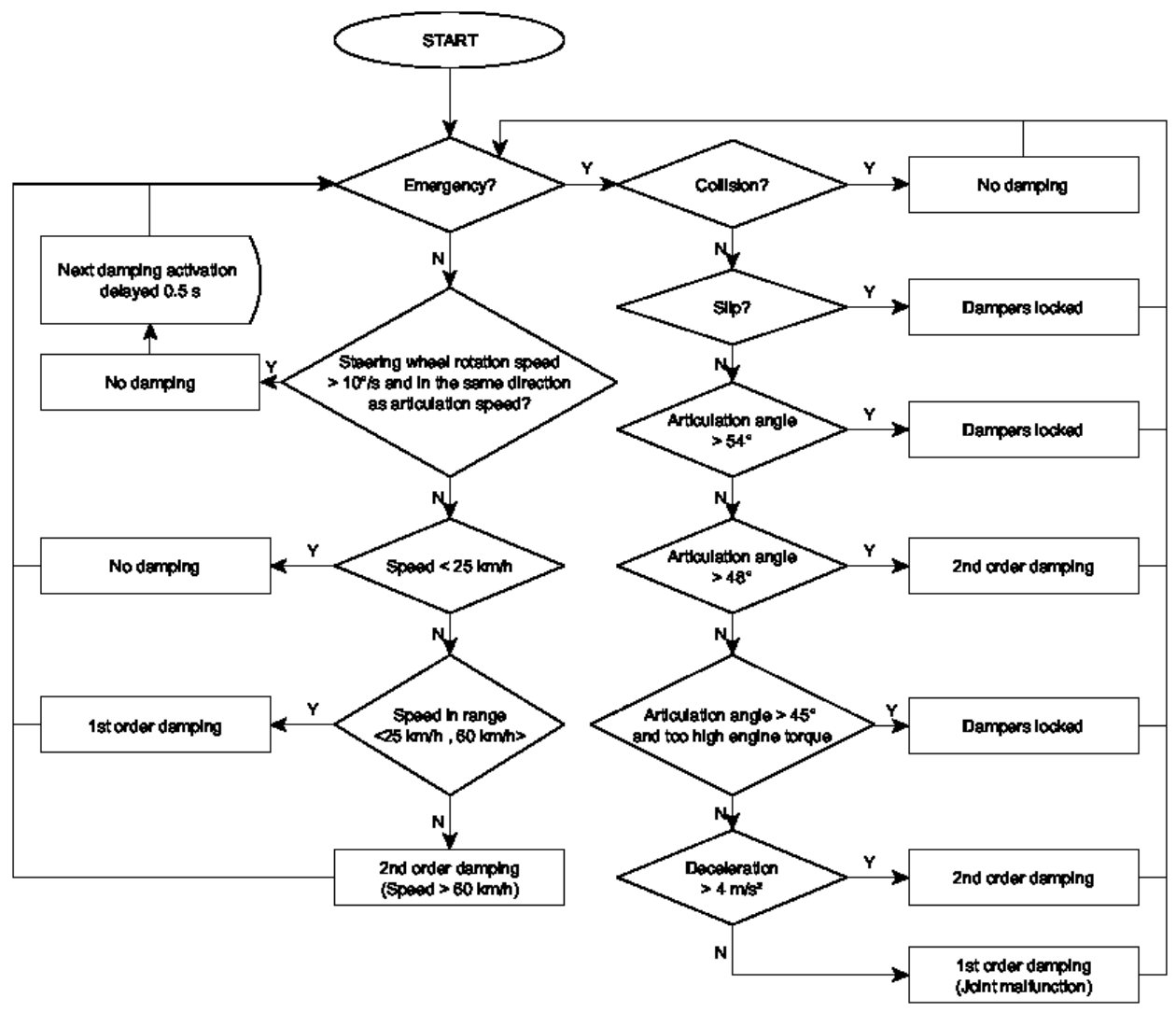

Fig. 6. The control algorithm

\subsection{Simulation}

The vehicle model was implemented in the LabVIEW environment. The simulation was performed with a constant step $(0.2 \mathrm{~ms})$ and the equations were solved using Runge-Kutta fourth-order method. Parameters of the vehicle model are presented in Table 1.

The simulated manoeuvres are: 90 degree turn (at $15 \mathrm{~m}$ and $30 \mathrm{~m}$ turning radius) and lane change (lane width $2.5 \mathrm{~m}$, manoeuvre time $4 \mathrm{~s}$ ). Each manoeuvre is simulated for empty and loaded vehicle. 
Table 1. The parameters of the vehicle model

\begin{tabular}{l|l}
\hline Parameter & \multicolumn{1}{c}{ Value } \\
\hline \multicolumn{1}{c}{$\begin{array}{c}\text { Front unit } \\
\text { empty/loaded }\end{array}$} \\
\hline$m_{1}$ & $10,170 / 16,740 \mathrm{~kg}$ \\
$J_{l}$ & $82,761 / 127,017 \mathrm{~kg} \cdot \mathrm{m}^{2}$ \\
$L 1 C 1$ & $2.875 / 2.525 \mathrm{~m}$ \\
$L 2 C 1$ & $2.255 / 2.605 \mathrm{~m}$ \\
$L C 1$ & $3.846 / 4.196 \mathrm{~m}$ \\
$F_{z 1}$ & $48.2 / 86.1 \mathrm{kN}$ \\
$F_{z 2}$ & $33.2 / 66.5 \mathrm{kN}$ \\
$K_{1}$ & $143 / 189 \mathrm{kN} / \mathrm{rad}$ \\
$K_{2}$ & $126 / 115 \mathrm{kN} / \mathrm{rad}$ \\
\hline \multicolumn{2}{c}{ Damper and Valve } \\
\hline$K_{b m}$ & $1.5 \mathrm{GPa}$ \\
$V_{0 / 1}, V_{0 / 2}$ & $0.00136 \mathrm{~m}^{3}$ \\
$A_{1}, A_{2}$ & $0.00341 \mathrm{~m}^{2}$ \\
$C_{d}$ & 0.611 \\
$\rho$ & $844 \mathrm{~kg} / \mathrm{m}^{3}($ Tellus DO10) \\
$A_{\text {orif } \min }$ & $10^{-12} \mathrm{~m}^{2}$ \\
$A_{\text {orif } \max }$ & $10^{-4} \mathrm{~m}^{2}$ \\
\hline
\end{tabular}

\begin{tabular}{ll}
\hline Parameter & \multicolumn{1}{c}{ Value } \\
\hline \multicolumn{1}{c}{$\begin{array}{c}\text { Rear unit } \\
\text { empty/loaded }\end{array}$} \\
\hline$m_{2}$ & $6,690 / 12,120 \mathrm{~kg}$ \\
$J_{2}$ & $40,335 / 77,742 \mathrm{~kg} \cdot \mathrm{m}^{2}$ \\
$L 3 C 2$ & $-1.488 /-0.519 \mathrm{~m}$ \\
$L C 2$ & $6.402 / 5.433 \mathrm{~m}$ \\
$F_{z 3}$ & $84.0 / 130.5 \mathrm{kN}$ \\
$K_{3}$ & $132 / 172 \mathrm{kN} / \mathrm{rad}$ \\
\hline \multicolumn{2}{c}{ Tyres } \\
\hline$C_{r r}$ & $0.008 \quad$ Articulation \\
$V_{t h r}$ & $0.004 \mathrm{~m} / \mathrm{s}$ \\
$\varepsilon$ & $0.0115 \mathrm{~m} / \mathrm{s}$ \\
$\mu$ & $0.9 \quad 0$ \\
$S_{n}$ & $0.781 \mathrm{~m}$ \\
\hline \multicolumn{2}{|c}{} \\
\hline$S 1$ & $1.857 \mathrm{~m}$ \\
$S 2$ & $0.648 \mathrm{~m}$ \\
\hline
\end{tabular}

\section{Results}

A summary of conditions, under which the manoeuvres were simulated is presented in Table 2 .

Table 2. Simulated manoeuvres.

\begin{tabular}{|c|c|c|c|c|c|}
\hline \multirow{2}{*}{ Manoeuvre } & \multicolumn{5}{|c|}{ Initial vehicle speed (+/- 1\%) } \\
\hline & $10 \mathrm{~km} / \mathrm{h}$ & $25 \mathrm{~km} / \mathrm{h}$ & $45 \mathrm{~km} / \mathrm{h}$ & $60 \mathrm{~km} / \mathrm{h}$ & $80 \mathrm{~km} / \mathrm{h}$ \\
\hline $\begin{array}{c}90^{\circ} \text { turn } \\
15 \text { m radius }\end{array}$ & $\begin{array}{c}\mathrm{Alg}=\mathrm{D} 0, \\
\mathrm{D} 1, \mathrm{D} 2, \mathrm{Dmax}\end{array}$ & $\begin{array}{c}\text { Alg, D0, } \\
\text { D1, D2, Dmax }\end{array}$ & $X$ & $\mathrm{X}$ & $\mathrm{X}$ \\
\hline $\begin{array}{c}90^{\circ} \text { turn } \\
30 \mathrm{~m} \text { radius }\end{array}$ & $\mathrm{X}$ & $\begin{array}{c}\text { Alg, D0, } \\
\text { D1, D2, Dmax }\end{array}$ & $\begin{array}{c}\mathrm{Alg}=\mathrm{D} 1, \\
\mathrm{D} 0, \mathrm{D} 2\end{array}$ & $\mathrm{X}$ & $\mathrm{X}$ \\
\hline $\begin{array}{l}\text { lane change } \\
2.5 \mathrm{~m} / 4 \mathrm{~s}\end{array}$ & $\mathrm{X}$ & $\mathrm{X}$ & $\mathrm{X}$ & $\begin{array}{c}\text { Alg }=\mathrm{D} 1, \\
\text { D0, } \\
\text { D2 = Dmax }\end{array}$ & $\begin{array}{c}\text { D0, Alg=D1= } \\
\text { D2=Dmax }\end{array}$ \\
\hline
\end{tabular}

$\mathrm{X}$ - not simulated; Alg - damping set according to the algorithm output; D0 - no damping enforced; D1 - 1st level damping enforced; D2 - 2nd level damping enforced; Dmax - dampers lock enforced; $(\mathrm{x}=\mathrm{y}=\ldots)$ - similar results achieved with configurations $\mathrm{x}, \mathrm{y}$, etc.

During simulation of the manoeuvres, movement direction of the vehicle was changed by setting the steer angle of the front axle. The simplified steering input followed trapezoidal and sinusoidal profiles for the 90 degree turn and lane change, respectively. All manoeuvres indicated in the Table 2 were successfully accomplished, i.e., the vehicle followed the required path and did not lose stability when its front axle returned to the straight-ahead position. 
As a measure of the quality of the applied control a mean absolute slip angle of the tyres was calculated for each manoeuvre (Fig. 7). As it can be seen, in most cases the control algorithm chooses the damping level which results in the lowest, or nearly the lowest, slip of the vehicle.

a) Lane change

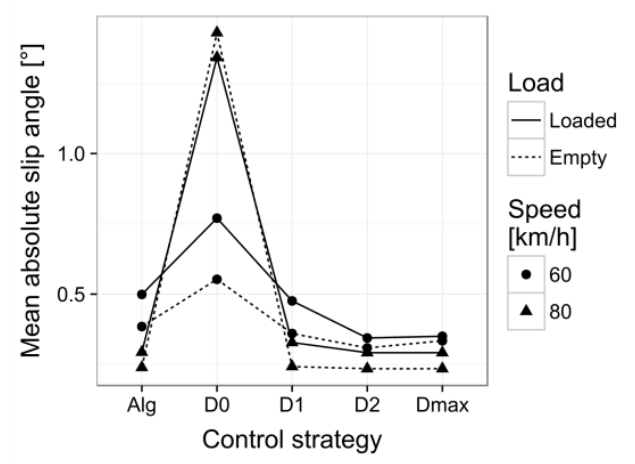

b) 90 degree turn

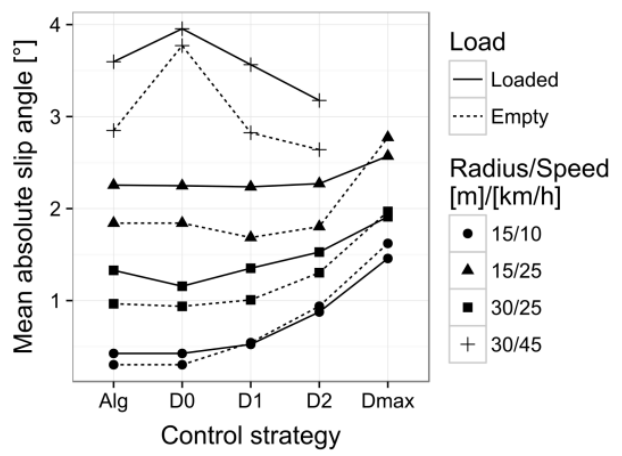

Fig. 7. The mean absolute slip angle for manoeuvres simulated with various control strategies; used abbreviations: according to Table 2 footnotes

Simulation of the lane change with no damping enforced showed a potentially dangerous situation. Such manoeuvre, performed at $60 \mathrm{~km} / \mathrm{h}$, was followed by self-limiting oscillations of the front and rear unit with respect to one another. However, after changing the speed to $80 \mathrm{~km} / \mathrm{h}$, the amplitude of these oscillations increased in time, what made the vehicle movement unstable. Loss of the articulation damping may result from a failure of the proportional valve and may lead to an accident, such as discussed in the accident report presented in [7].

\section{Sensor layer}

The control algorithm for the articulation requires application of only four sensors: sensor of angular position of the steering wheel of the vehicle (embedded in the steering column), sensor of angular position between the two units of the vehicle and two sensors indicating pressure in hydraulic dampers (embedded in the dampers structure). So, as far as the algorithm is concerned, only one additional sensor must be installed.

However, more sensors are required for diagnostic purposes. It is highly probable that some members of the articulation will wear out or get damaged within the assumed life of this device (of 7 years at least). These members are: the rolling bearing, metalastiks ( 2 pcs.), rubber bumping blocks limiting the angular range of motion of the articulation ( 2 pcs.) and mountings of the hydraulic dampers ( 2 pcs.). Except for the rolling bearing, all the other members require application of some proximity sensors, detecting an excessive range of relative linear motion within their vicinity (in the case of metalastiks, displacements in two perpendicular axes).

Let us briefly analyze each kind of the required sensors, starting with the angular position of the articulation. A typical approach is to apply an absolute angle encoder or an incremental angle encoder coupled with an additional sensor indicating some reference mutual angular position (e.g. when both units of the vehicle are aligned). However, such solution is protected by some relevant patent claims. Therefore, other propositions were put forward. One of them is application of two sensors, one in each unit of the vehicle, indicating an absolute angular position of the unit. For this purpose, a magnetometer, a 
gyroscope (especially MEMS sensor) or even a whole Inertial Measurement Unit (IMU) could be used (there are available automotive versions of IMU fabricated in microtechnology, e.g. for motorcycle ABS/TCS systems [8]). Another idea is to measure the mutual angular position indirectly. Then, measurements of a linear displacement of an additional member, its strain or an interaction force can be employed.

Because of the significance of the considered sensor, it would be advantageous to add another redundant sensor of angular position of the articulation for diagnostic purposes. This sensor could be employed also by the control unit in the case of a failure of the primary sensor. The sensor can be also reduced to a detector, indicating only occasionally a selected position of the units (e.g. while aligned), and only then comparing its output signal with its counterpart generated by the main sensor of angular position of the articulation.

With regard to the rolling bearing, a standard diagnostics requires temperature and vibration measurements and monitoring of the generated noise as well as lubrication conditions [9]. However, operation of the considered rolling bearing will be untypical due to its low rotational speed and rather an intermittent cycle of operation. It will be rather its radial plays (i.e. small linear displacements) that will be indicators of wear. It is difficult to tell how effective will vibration measurements be in this case. However, application of accelerometers enables monitoring both vibration as well as calculation of linear displacements (e.g. by integrating the output signal). The second option is quite easy to be realized, especially at a specified frequency (e.g. one of the natural frequencies of the articulation), as the measurement range and frequency are strictly related [10]; in such a case, by transforming the equation of motion we obtain the following formula [11]:

$$
\mathrm{x}=\frac{\mathrm{a}}{\omega^{2}}=\mathrm{a} \cdot \mathrm{const}
$$

where: $x$ - displacement, $a$ - acceleration, $\omega$ - angular frequency.

So, according to (29), it is very easy to determine the maximal linear displacement on the basis of accelerometer indication, provided it is at a fixed and known frequency. However, to determine a displacement between two different points assigned to different structural members (e.g. a pivot and a bearing), always a pair of accelerometers is necessary in order to calculate a difference of the respective linear displacements. Moreover, there are other complications connected with application of accelerometers, like e.g. a necessity of their appropriate alignment [12] or calibration of their output signals [13]. Yet, these issues are typical and can be easily dealt with.

As far as the wear or damage of the other aforementioned members of the articulation (metalastiks, bumping blocks, mountings of the dampers) are concerned, the same kind of measurement/sensors can be applied. However, in the case of metalastiks dual-axis accelerometers must be employed, whereas in other cases uni-axial accelerometers would be satisfactory.

To summarize, it seems an advantageous solution to apply MEMS sensors, especially accelerometers in the sensor layer of the articulation. These sensors are cheap and robust, have their own self-test functionality and some models are integrated with temperature sensors. Thus, vibration, linear displacement and temperature measurements can be realized using one sensor (or one pair of sensors). Some additional effects can be obtained using appropriate spatial arrangement of MEMS accelerometers, as described e.g. in [14,15] - in this way, e.g. a tilt angles of the vehicle units can be determined or accuracy of measurements can be increased, if need be. Tilt measurements can be employed to increase safety of the vehicle (e.g., by comparing rolls of the front and the rear unit). 


\section{Conclusions}

The simulation of motion of the articulated vehicle showed that the proposed control algorithm ensures stability of the motion under the tested conditions. A possibility of losing the damping in the articulation as a result of a hardware failure (i.e., failure of the proportional valve) is indicated as an important risk source for the discussed control system, according to the simulation results.

It was managed to develop quite simple sensor layer to be employed by the control algorithm and diagnostic system. As proven by the presented analysis, application of MEMS sensors seems to be an advantageous solution, especially for diagnostic purposes, due to their low-cost, high reliability, self-test function and robustness.

This work has been supported by The National Centre for Research and Development, within a project, "Elaboration of innovative inter-cars articulations having a unique lighter design capable of absorbing crash energy in order to ensure passenger safety in public transport".

\section{References}

1. K. Kim, H. Guan, B. Wang, R. Guo, F. Liang, Active steering control strategy for articulated vehicles, Front. Inf. Technol. Electron. Eng. 17, 576-586 (2016)

2. S. T. Oreh, R. Kazemi, S. Azadi, A new desired articulation angle for directional control of articulated vehicles, Proc. Inst. Mech. Eng. Part K J. Multi-body Dyn. 226, 298-314 (2012)

3. R. Rusev, R. Ivanov, G. Staneva, G. Kadikyanov, A Study of the Dynamic Parameters Influence Over the Behavior of the Two-Section Articulated Vehicle During the Lane Change Manoeuvre, Transp. Probl. 11, 29-40 (2016)

4. H. Dugoff, P. Fancher, L. Segel, An Analysis of Tire Traction Properties and Their Influence on Vehicle Dynamic Performance, SAE Trans. 79 (1970)

5. O.A. Bauchau, H. Liu, On the Modeling of Hydraulic Components in Rotorcraft Systems, Journal of the American Helicopter Society 51, 175-184 (2006)

6. B. Titurus, J. L. du Bois, N. Lieven, Modeling and testing of a semiactive hydraulic damper in periodic working regimes, AIAA Journal 50, 844-854 (2012)

7. G. Rosvall, H. Elinder, Accident involving a Mercedes Benz articulated bus, registration no STK 595, on Glömstavägen in Stockholm/Huddinge, AB County, Sweden, on the 2nd of April 2002, The Swedish Accident Investigation Board, Report RO 2003:01e, ISSN 1400-5751 (2003)

8. S. Łuczak, Tilt Measurements in BMW Motorcycles, in R. Jabłoński, R. Szewczyk (Eds.), Recent Global Research and Education: Technological Challenges. (Springer International Publishing, Cham, Switzerland, 2017)

9. SKF Poradnik Obstugi Technicznej Łożysk, (SKF Group, 2010)

10. M. Looney, An Introduction to MEMS Vibration Monitoring, Analog Dialogue 48-06, (Analog Devices, USA, 2014)

11. R. Heaton, S. Hewitt, The use of Operating Deflection Shapes (ODS) to model the vibration of sanders and polishers. (Health\&Safety Laboratory, Buxton, UK, 2006)

12. S. Łuczak, Fast Alignment Procedure for MEMS Accelerometers, in R. Jabłoński, T. Brezina (Eds.), Advanced Mechatronics Solutions. (Springer International Publishing, Cham, Switzerland, 2016) 
13. S. Łuczak, Experimental Studies of Hysteresis in MEMS Accelerometers: A Commentary. IEEE Sensors J. 15, 3492-3499 (2015)

14. S. Łuczak, Guidelines for Tilt Measurements Realized by MEMS Accelerometers. Int. J. Precis. Eng. Manuf. 15, 2012-2019 (2014)

15. S. Luczak, R. Grepl, M. Bodnicki, Selection of MEMS Accelerometers for Tilt Measurements, J. Sensors 2017, Article ID 9796146 (2017) 